\title{
Treatment of non-ampullary duodenal epithelial tumors: Does phenotype matter?
}

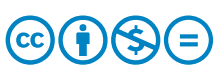

\author{
Authors \\ Yohei Yabuuchi ${ }^{1}$, Noriya Uedo ${ }^{1,2}$ \\ Institutions \\ 1 Division of Endoscopy, Shizuoka Cancer Center, \\ Shizuoka, Japan \\ 2 Department of Gastrointestinal Oncology, Osaka \\ International Cancer Institute, Osaka, Japan
}

Bibliography

Endosc Int Open 2021; 09: E1303-E1305

DOI 10.1055/a-1495-5101

ISSN 2364-3722

(c) 2021. The Author(s).

This is an open access article published by Thieme under the terms of the Creative Commons Attribution-NonDerivative-NonCommercial License, permitting copying and reproduction so long as the original work is given appropriate credit. Contents may not be used for commercial purposes, or adapted, remixed, transformed or built upon. (https://creativecommons.org/licenses/by-nc-nd/4.0/)

Georg Thieme Verlag KG, Rüdigerstraße 14,

70469 Stuttgart, Germany

Corresponding author

Noriya Uedo, Department of Gastrointestinal Oncology,

Osaka International Cancer Institute, 3-1-69 Otemae,

Chuo-ku, Osaka 541-8567, Japan

Fax: +81-6-6945-1900

noriya.uedo@gmail.com
Although non-ampullary duodenal epithelial tumors (NADETs) are relatively rare in the general population, opportunities for endoscopic detection and treatment of them have been increasing due to advances in endoscopic equipment and awareness of the disease [1]. Because the prognosis for invasive duodenal carcinoma is dismal and surgical treatment with pancreatoduodenectomy can result in morbidity and death, less invasive prophylactic treatment of NADETs with endoscopic resection significantly benefits patients. Nevertheless, endoscopic treatment of NADETs is often difficult because the narrow and tortuous duodenal lumen restricts endoscopic maneuvers and thin duodenal walls and secretion of bile and pancreatic juice into the duodenal lumen induce severe delayed adverse events (AEs), such as bleeding and perforation [2]. Accordingly, it is important to establish practical indications for when NADETs should or should need be treated with endoscopic resection.

With recent advances in immunohistochemical staining, NADETs have been classified into two major types - intestinal and gastric - according to mucin expression. Mucin phenotype is determined according to positivity against: 1) cluster of differentiation 10 (CD10), which is a marker of enteric brush border: 2) mucin 2 (MUC2), which is a major intestinal mucin expressed in goblet cells of the small intestine and colon; 3) mucin 5AC (MUC5AC), which is produced in the gastric foveolar epithelium; and 4) mucin 6 (MUC6), which is expressed in the pyloric and cardiac glands and mucous neck cells. Tumors positive for CD10 and MUC2 are classified as intestinal while tumors positive for MUC5AC and MUC6 are gastric.
Recently, an association between the mucin phenotype and clinicopathological features of NADETS, particularly tumor location and histological grade, has been reported in several studies. First, gastric NADETs are likely to develop on the oral side, and especially the proximal half, of the ampulla of Vater. Brunner's glands are compound submucosal glands that produce a mucus-rich alkaline secretion that contains bicarbonate and protects the duodenal mucosa from the acidic gastric content. The result is in an alkaline condition that activates intestinal enzymes and lubricates the intestinal walls. Brunner's glands are distributed in the duodenum on the oral side of the ampulla of Vater and may transform into metaplastic gastric epithelium as a result of chronic exposure to the gastric acid [3]. An association has been suggested between development of gastric NADETs and presence of Brunner's gland hyperplasia, gastric foveolar metaplasia, and heterotopic gastric mucosa [46]. Recent studies have shown that gastric foveolar metaplasia and heterotopic gastric mucosa are more frequently observed in mucosa adjacent to gastric than intestinal NADETs, while Brunner's gland hyperplasia is commonly found irrespective of tumor phenotype $[7,8]$. Moreover, a significant proportion of gastric foveolar metaplasia and heterotopic gastric mucosa harbored GNAS and/or KRAS mutations, which are commonly seen in gastric NADETs, suggesting that his type of NADET in the proximal duodenum develops with metaplastic gastric epithelium as a precursor [9] ( $\triangleright$ Fig. 1). Because Brunner's glands are anatomically distributed in the proximal duodenum, gastric NADETs are prone to develop in the same area. Second, gastric NADETs show more aggressive biological behavior than intes- 


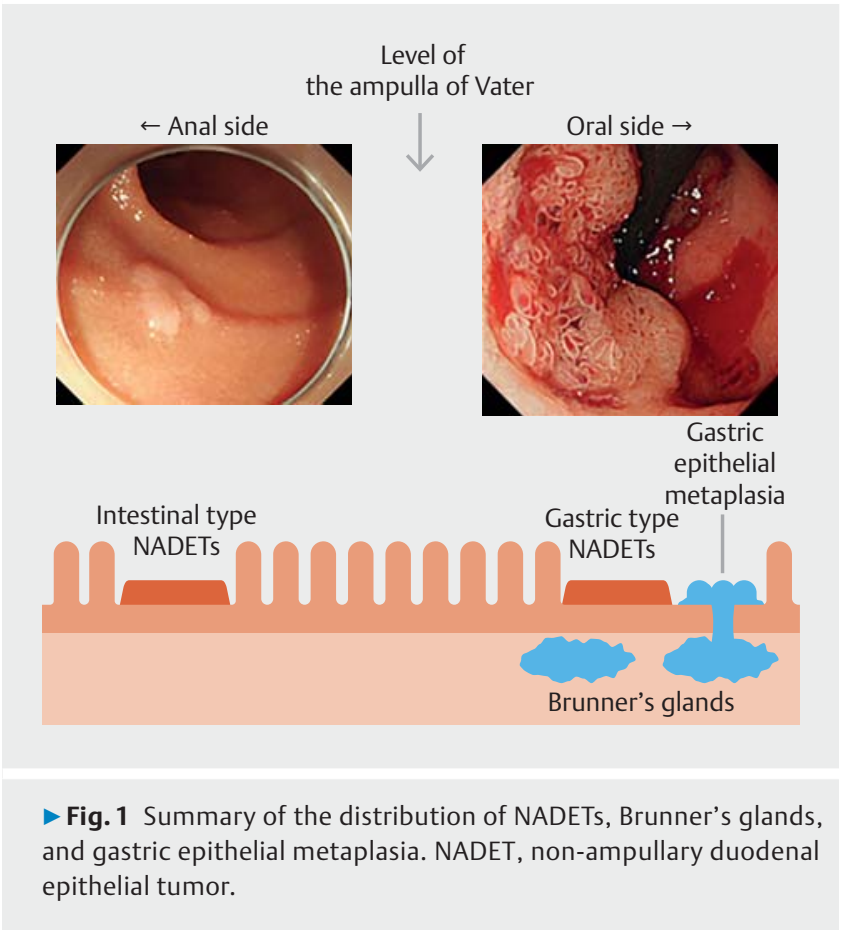

tinal NADETs. In surgically resected cases, patients with gastric NADETs had worse overall and disease-free survival than those with intestinal NADETs [4]. Several observational studies have shown that gastric NADETs have a higher proportion of highgrade dysplasia or submucosal invasive cancer than intestinal NADETs $[7,8,10,11]$. Moreover, among gastric NADETs, most submucosal invasive cancers manifested as small lesions measuring $\leq 10 \mathrm{~mm}$ [8]. Therefore, gastric NADETs should be treated regardless of size because of their malignant potential.

In this issue of Endoscopy International Open, Toya et al. investigate the association between mucin phenotypes of NADETs and clinical outcomes of endoscopic resection [12]. In that study, as previously reported, the proportions of highgrade dysplasia or submucosal invasive cancer in gastric NADETs were higher than those in the intestinal NADETs. However, no significant difference was observed between mucin phenotypes and outcomes of endoscopic resection such as en bloc resection and $\mathrm{R} 0$ resection rates. AEs such as intraoperative perforation and retroperitoneal emphysema occurred in four cases of intestinal SNADETs (5.7\%), but no AEs occurred in patients with gastric NADETs. Serious delayed AEs frequently develop in lesions in the side distal from the ampulla of Vater because of exposure of the resection wound to pancreatic juice or bile [2]. Because gastric NADETs are predominantly located in the proximal duodenum, the low incidence of AEs may be due to the lesion location rather than the mucin phenotypes. Although the study had a significant limitation in the small number of subjects, which resulted in low statistical power and difficulty in adjusting for confounders, their conclusion statement seemed theoretically consistent with results from other publications. The facts of high histological grades and low AE rates might even promote performance of aggressive treatment by endoscopic submucosal dissection for gastric NADETs.
Gastric NADETs appear to be a good indication for endoscopic resection; however, the diagnosis of mucin phenotype must be made before treatment. Recently, some studies have investigated the association between endoscopic appearance and mucin phenotypes of NADETs. Reddish color, polypoid appearance, and lobular or granular surface pattern in white-light endoscopy [13], oval-shaped marginal epithelium, dense pattern, and dilation of the intervening part on magnifying endoscopy with narrow-band imaging [13], and pinecone pattern on magnifying crystal violet chromoendoscopy [14] were more frequently seen with gastric than intestinal NADETs. Therefore, these findings can be used for prediction of gastric NADETs.

Mucin phenotype may be one useful indicator for decisionmaking about endoscopic resection of NADETs because gastric NADETs are associated with high malignant potential and low rates of AEs by pre-ampullary location. This concept warrants further verification in future large-scale studies, preferably cohorts.

\section{Competing interests}

The authors declare that they have no conflict of interest.

\section{References}

[1] Goda K, Kikuchi D, Yamamoto Y et al. Endoscopic diagnosis of superficial non-ampullary duodenal epithelial tumors in Japan: Multicenter case series. Dig Endosc 2014; 26: (Suppl. 02): 23-29

[2] Inoue T, Uedo N, Yamashina T et al. Delayed perforation: a hazardous complication of endoscopic resection for non-ampullary duodenal neoplasm. Dig Endosc 2014; 26: 220-227

[3] Kushima R, Manabe R, Hattori T et al. Histogenesis of gastric foveolar metaplasia following duodenal ulcer: a definite reparative lineage of Brunner's gland. Histopathology 1999; 35: 38-43

[4] Ushiku T, Arnason T, Fukayama M et al. Extra-ampullary duodenal adenocarcinoma. Am J Surg Pathol 2014; 38: 1484-1493

[5] Kushima R, Stolte M, Dirks K et al. Gastric-type adenocarcinoma of the duodenal second portion histogenetically associated with hyperplasia and gastric-foveolar metaplasia of Brunner's glands. Virchows Arch 2002; 440: 655-659

[6] Kushima R, Rüthlein H], Stolte M et al. 'Pyloric gland-type adenoma' arising in heterotopic gastric mucosa of the duodenum, with dysplastic progression of the gastric type. Virchows Arch 1999; 435: 452-457

[7] Matsueda K, Uedo N, Kitamura M et al. Pre-ampullary location and size $\geq 10 \mathrm{~mm}$ are independent predictors for high-grade superficial non-ampullary duodenal epithelial tumors. J Gastroenterol Hepatol 2020: doi:10.1111/jgh.15317

[8] Yoshida M, Shimoda T, Abe M et al. Clinicopathological characteristics of non-ampullary duodenal tumors and their phenotypic classification. Pathol Int 2019; 69: 398-406

[9] Matsubara A, Ogawa R, Suzuki $\mathrm{H}$ et al. Activating GNAS and KRAS mutations in gastric foveolar metaplasia, gastric heterotopia, and adenocarcinoma of the duodenum. Br J Cancer 2015; 112: 13981404

[10] Toba T, Inoshita N, Kaise M et al. Clinicopathological features of superficial non-ampurally duodenal epithelial tumor; gastric phenotype of histology correlates to higher malignant potency. J Gastroenterol 2018; 53: 64-70 
[11] Minatsuki C, Yamamichi N, Inada Kl et al. Expression of gastric markers is associated with malignant potential of nonampullary duodenal adenocarcinoma. Dig Dis Sci 2018; 63: 2617-2625

[12] Toya Y, Endo M, Yamada S et al. The mucin phenotype does not affect the endoscopic resection outcome of non-ampullary duodenal epithelial tumors. Endosc Int Open 2021; 09: E1297-E1302
[13] Akazawa Y, Ueyama H, Tsuyama S et al. Endoscopic and clinicopathological features of superficial non-ampullary duodenal tumor based on the mucin phenotypes. Digestion 2020: doi:10.1159/ 000508040

[14] Toya Y, Endo M, Akasaka R et al. Clinicopathological features and magnifying chromoendoscopic findings of non-ampullary duodenal epithelial tumors. Digestion 2018; 97: 219-227 